\title{
Analogical Learning in Negotiation Teams: Comparing Cases Promotes Learning and Transfer
}

\author{
JEFFREY LOEWENSTEIN \\ Columbia University \\ LEIGH THOMPSON \\ DEDRE GENTNER \\ Northwestern University
}

\begin{abstract}
We used structure-mapping theory (Gentner, 1983) to study learning in negotiation teams. We instructed some teams to compare two training cases and identify a key negotiation principle; other teams were given the same two cases to study and analyze separately. Teams who compared the two cases during the training period were more likely to transfer a key value-added strategy to a novel face-to-face, two-party negotiation situation than were teams who analyzed the same two cases separately. In fact, analyzing cases separately was no better than no training at all. Teams of negotiators showed comparable levels of knowledge transfer to solo negotiators.
\end{abstract}

At the forefront of nearly all management issues and challenges is the ability to learn, change, and adapt. Management educators in universities as well as corporate trainers face two inextricably linked challenges: offering relevant strategies and proven techniques to their students and clients and at the same time, providing a foundation so that the principles are actually used on the job. Management educators and corporate trainers, in the new era of knowledge and information technology, have more choices than ever when it comes to crafting the delivery of knowledge and skills to their students, employees, and clients. However, the choices can be daunting, and the relevant research regarding the effectiveness of different training techniques is often not readily accessible. We describe here the effectiveness of a training technique in management classrooms that represents an advance over traditional forms of the case method. The technique, analogical learning, is

This research was supported by a fellowship from Northwestern University's Dispute Resolution Research Center to Jeffrey Loewenstein, and awards from the National Science Foundation, SES-9870892, to Leigh Thompson, and Office of Naval Research Contract, \#N00014-92-J-1098, to Dedre Gentner. based on theoretical research in cognitive psychology. Its application to management classrooms is straightforward, and implementation costs are low.

The study addresses three questions: First, we examine whether team learning and task performance is facilitated if team members compare cases-what we have called analogical encoding-versus team members analyzing cases separately or team members not analyzing any training cases. Second, we consider whether separate analysis of training cases yields better task performance than receiving no training cases. Third, we explore whether, following team training, team or individual performance is facilitated. Finally, we consider the implications of our investigation for the practice of management education and training.

\section{ANALOGICAL REASONING AND LEARNING}

Anclogy is recognized as both a source of new ideas and a means for communicating new ideas, thus, analogy is tightly bound to learning (Gentner, Holyoak, \& Kokinov, 2001). Researchers studying diverse areas, such as marketing (Gregan- 
Paxon \& Roedder John, 1997), critical thinking (Halpern, 1998) and managerial problem solving (Isenberg, 1986) have implicated analogy in learning. Typically, claims about learning by analogy are that people can use a well-understood topic to make sense of a new topic. The result can be local, mundane learning (e.g., a science teacher explaining that $\alpha$ heart is like $\alpha$ pump), or $\alpha$ breakthrough discovery (e.g., the early $20^{\text {th }}$ century physicist Rutherford advanced atomic physics by drawing an analogy between the structure of the solar system and the structure of an atom; Gentner, 1983).

\section{Failures of Learning}

We argue that most failures of learning are not attributable to a lack of knowledge but to people's inability to retrieve the right knowledge at the right time. Indeed, people often fail to draw analogies when it would be helpful for them to do so (e.g., Gick \& Holyoak, 1980; Pfeffer \& Sutton, 2000). In this sense, potentially useful knowledge can remain inert because people fail to recall it to solve a new but related problem. For example, in one investigation, people were presented with the proverbs: "all that glitters is not gold" and "don't judge $a$ book by its cover." Despite their similar meanings, the first, "all that glitters is not gold" in most cases did not remind people of "don't judge a book by its cover," (Schumacher \& Gentner, 1987). Instead, people were reminded of "every cloud has a silver lining." The same inert knowledge problem has been found in mathematics. For example, Ross (1984, 1987) trained students on probability problems (e.g., for the principle of waiting time, $q^{(k-1)} p$ : if there is $a 3 / 8$ chance of rain each day, what is the chance there is no rain for the next 3 days?), then tested whether they could apply the principles to new problems. He found that students were more likely to apply principles appropriately if the test problem shared specifics and context with the initial problem (i.e., the following was another problem about weather; $73 \%$ transfer) than if it was from $\alpha$ new context (e.g., $\alpha$ problem about golf; $43 \%$ transfer). Analysis of these studies suggests that people focus on superficial details during learning, and recall examples from memory primarily on the basis of those superficial details (Gentner \& Landers, 1985; Gentner, Rattermann, \& Forbus, 1993; Holyoak \& Koh, 1987; Keane, 1988; Ross, 1984, 1987). Thus, learning and transfer pose two primary cognitive challenges: schema abstraction (deriving principles or schemas from examples), and analogical retrieval (recalling those schemas later to solve new problems).

\section{Anclogical Encoding}

To address these cognitive challenges, we examine a second role for analogy in learning: the mutual alignment of two novel situations. Drawing an analogy between two situations, even if neither is well understood, focuses learners on what the two situations have in common. The process of comparing cases encourages determining the largest coherent system shared by the cases, and the cases are then understood with respect to this common system. For example, drawing the analogy between the solar system and an atom mentioned earlier emphasizes smaller units revolving around larger units due to attractive forces (and deemphasizes the properties of the units themselves, such as their coloration, temperature, ability to support life, etc.). We call this process analogical encoding to stress that drawing analogies during learning leads to understanding the cases differently (i.e., with respect to what they have in common) than if those cases were analyzed independently (i.e., with respect to whatever is salient in the individual cases, which is often superficial details; Loewenstein, Thompson, \& Gentner, 1999; Thompson, Gentner, \& Loewenstein, 2000).

The structure-mapping theory of analogy (Gentner, 1983, 1989; Gentner \& Markman, 1997) claims that elements and relations among elements both enter into the comparison process, with structurally connected relational commonalities typically dominating object-level commonalities due to people's tacit preferences for structure. For example, $1-2-3$ is $a$ better analogy to $a-b-c$ than is $c-a-b$. Although there is element-level similarity between $a-b-c$ and $c-a-b$ (i.e., they are similar on the surface), the relations among elements are similar between $a-b-c$ and 1-2-3 (i.e., the elements are structured similarly). Thus, structure mapping predicts that when people draw a comparison (provided there is a structural match across items), they will accentuate structural commonalities. The analogical encoding process should help learners understand relational structures that are embedded in concrete examples. These relational structures, when divorced from the examples, can be considered schemas or principles. If people can recognize principles in cases during learning, this should facilitate recalling those principles later. even without the support of a surface similarity match.

On the basis of these conclusions about the comparison process, we predict drawing comparisons should facilitate learning and transfer relative to examining two examples separately. Further, because separate analysis of study cases should 
lead to situated, context-specific learning, it should not increase transfer to new contexts unless these contexts are highly "surface similar" to the learning cases. Although separate case analysis should lead to some memory for the cases themselves, the underlying principles within them should remain inert knowledge. Thus, perhaps rather surprisingly, we predict that people who study two cases separately will show little or no advantage on a later analogous test problem over people who receive no study cases.

\section{TEAM LEARNING IN NEGOTLATION}

Team negotiation is an emerging area of interest (Brodt \& Thompson, 2001), as is learning in teams (e.g., Argote, 1999) and learning in negotiation (Lewicki, 1997; Wheeler, 2000). However, present theory is mixed as to the circumstances under which teams enhance learning and negotiation performance.

Take for example the following different claims as to whether team learning enhances understanding relative to individual learning. Teams yield process gains if the task can be characterized by $\alpha$ "truth wins" or best member model (Steiner, 1972). Further, there is evidence that team learning can be synergistic. For example, Schwartz (1995) found that pairs of learners better grasped a schema from a single concrete example than did individuals; Schwartz attributed the difference to team members fleshing out each other's understandings. However, teams also exhibit process losses due to social and cognitive shortcomings (e.g., production blocking), as frequently seen in studies of creativity and brainstorming (Diehl \& Stroebe, 1987; Paulus \& Dzindolet, 1993).

There are also differing claims as to whether teams of negotiators will outperform individuals. On the positive side, negotiating teams might have greater attentional capacity, and they may share more information than do individuals (Brodt \& Thompson, 2001; O'Connor, 1997; Thompson, Peterson, \& Brodt, 1996). On the negative side, Schopler and Insko (1992; Insko \& Schopler, 1987) found that teams engage in a greater degree of competitive behavior than do solo negotiators. Competitive behavior is likely to increase the use of habitual responses rather than novel responses, and hence, using the new study cases could be less likely among teams than among individuals. In sum, the question remains open as to whether team learning will foster understanding as a result of reading the study cases, and whether team performance will enhance knowledge transfer from the study cases to the face-to-face negotiation.
We explore the acquisition and use of an important but difficult negotiation skill: contingent contracts. Contingent contracts, defined broadly, function like bets: Parties specify terms that hinge on the uncertain outcome of $\alpha$ future event (Bazerman \& Gillespie, 1999; Lax \& Sebenius, 1986). Some subtypes of contingent contracts are commonly used in business (e.g., performance-based pay, or call options), but many other opportunities for use exist that are idiosyncratic. For example, Lax and Sebenius (1986: 95) described $\alpha$ situation in which $\alpha$ city and a firm building an electricity plant disagreed over the price of electricity. This could have led to an impasse, but instead they realized their differences resulted from differing forecasts over the price of oil ( $\alpha$ crucial fuel for the plant) and generated an agreement contingent upon future oil prices. That is, they tied the future price of electricity charged to the city to future oil prices. Our research question is this: Can teams derive the contingent contract schema from concrete examples and subsequently be able to apply it to a novel negotiation situation?

\section{INVESTIGATION}

This investigation examines whether negotiation teams benefit from analogy training. In prior research, we investigated analogical learning by asking individuals to analyze each case separately ("Separate Cases" condition) or to compare the two cases ("Comparison" condition; Loewenstein et al.. 1999; Thompson et al., 2000). Next, we measured the extent to which learners used the strategy outlined in the training case in their subsequent negotiation. We found that Comparison group participants showed a more than twofold transfer advantage relative to Separate Cases group participants (summarized in Table 1). Inspection of our process data revealed that the quality of peoples' abstractions of the initial cases was a strong predictor of subsequent transfer. In sum, drawing comparisons, more so than studying cases separately, led to deriving abstractions, which in turn led to transfer.

Here, we examine whether teams of learners will also benefit by comparing cases. Learning in teams may eliminate or magnify the comparison advantage found among individuals. We investigate the performance of $\alpha$ baseline group that does not receive training to determine whether separate case study represents an advantage over no case study. Thus, we asked teams of managers and management students to analyze training cases embodying contingent controcts. After studying cases, teams collectively prepared $\alpha$ report. Other 
TABLE 1

Proportion of Participants Who Formed Contingency Contracts by Test Condition (Number Formed/Number of Negotiation Groups)

\begin{tabular}{llll}
\hline $\begin{array}{c}\text { Negotiation } \\
\text { Performance }\end{array}$ & $\begin{array}{c}\text { Training } \\
\text { Context }\end{array}$ & Training TYpe & $\begin{array}{c}\text { Proportion Forming } \\
\text { Contingent Contracts }\end{array}$ \\
\hline Team & None & None & $.25(42 / 171)$ \\
Team & Team & Separate Cases & $.26(5 / 19)$ \\
Team & Team & Comparison & $.37(7 / 19)$ \\
& & Total & $.32(12 / 38)$ \\
Solo & None & None & $.19(8 / 42)$ \\
Solo & Team & Separate Cases & $.17(3 / 18)$ \\
Solo & Team & Comparison & $.41(17 / 41)$ \\
& & Total & $.34(20 / 59)$ \\
Solo & Solo & Separate Cases & $.24(20 / 83)^{\alpha}$ \\
Solo & Solo & Comparison & $.58(47 / 81)^{\alpha}$ \\
& & Total & $.41(67 / 164)$ \\
\hline
\end{tabular}

${ }^{\alpha}$ These groups are summed across data collected previously and are shown here collapsed across those prior studies (from Gentner et al., under review; Loewenstein et al., 1999; Thompson et al., 2000). They are presented for comparison purposes.

negotiators were not given training. Everyone then engaged in a face-to-face negotiation situation. Some teams remained intact; others were dissolved and individuals negotiated alone. Our primary measure was whether negotiating groups then formed contingency contracts. We predicted that drawing comparisons should increase the likelihood that participants would successfully transfer the contingent contract schema from the cases to the negotiation. A secondary measure was whether contingent contracts that were formed created greater joint expected value than other contracts. Our investigation was carried out in actual management training courses with participants who were highly motivated to learn.

\section{METHODS}

\section{Participants}

A group of 270 masters of management (MBA) students and middle-level sales managers participated in the training study. An additional 1,110 MBA students and middle-level sales managers served to establish baseline performance.

\section{Design}

We crossed three types of training (team comparison training, team separate case training, or no training) with two types of negotiation performance ([intact] team or [dissolved team] solo).

\section{Procedure}

The procedure consisted of two phases: training and face-to-face negotiation. During the training phase, we gave participants two training cases to read in a packet entitled "Negotiation Warm-up Anclysis." The cases were approximately 225-word descriptions of negotiation situations involving $\alpha$ conflict between individuals. The cases provided concrete details and context information and outlined a clear and elegant solution to the conflict; namely, the deployment of $\alpha$ contingency contract. One case described a merchant and buyer negotiating over the shipment of goods; the other described two brothers negotiating their inheritance of a working farm (see Loewenstein et al., 1999, for the full cases). Participants were given approximately 20 minutes to read and discuss the cases with their randomly assigned teammate. In the Separate Cases condition, teams were instructed to analyze each case individually: "What is going on in this negotiation? Please describe the solution and say how successful you think it is." In the Comparison condition, teams were instructed to compare the two cases: "What is going on in these negotiations? Think about the similarities between these two cases. What are the key parallels in the two negotiations? Please describe the solution and say how successful you think it is." Participants wrote answers to these questions as a team, which they signed and submitted to their instructors.

Next, participants engaged in a face-to-face negotiation. The negotiation task (1), allowed an opportunity for a value-added contingency contract; (2), contained no surface-level similarity to the two training cases; (3), allowed participants to negotiate either one-on-one or in teams; and (4), allowed for quantifying agreement outcomes to ensure that the contingent contracts were beneficial. In the "Team" conditions ( $N=38$ quartets), pairs who had 
studied together stayed intact and negotiated as $\alpha$ team against another team. In the "Solo" conditions ( $N=59$ dyads), the teams were dissolved and individuals negotiated on their own. For their negotiations, participants randomly received one of two roles to play (buyer or seller) and negotiated either team on team or individual on individual with someone from the same training condition. The participants were allowed up to 60 minutes to negotiate, at the conclusion of which they were asked to complete and sign a contract specifying the nature of their agreement.

\section{RESULTS}

\section{Negotiation Performance}

Analogy training led to better performance than separate cases or no training. Teams that compared cases $(n=24 / 60=40 \%$ ) were more likely to form $\alpha$ contingent contract in the actual, face-toface negotiation than were those who analyzed the cases separately $(n=8 / 37=22 \%$ ), a marginal association, $\chi^{2}(N=97,1)=3.50, p=.06$ (see Table 1$)$. Comparison training, but not separate case training, led to an advantage over no training at all. Members of the Comparison group negotiating individually were more likely to form contingent contracts than were those in the Baseline group, $\chi^{2}$ $(N=83,1)=4.95, p<.05$, but participants in the Separate Cases group were not, $\chi^{2}(N=60,1)<1$, $n s$. Combining across the different training instructions (i.e., comparison and separate cases), we found no reliable difference in generating contingent contracts between negotiations among intact teams ( $n=12 / 38=32 \%$ ) and negotiations among dissolved teams, that is, "solo" individuals ( $n=20 / 59=34 \%$ ), $\chi^{2}<1$, ns. Collapsing across negotiation performance and training context to examine training type, almost twice as many Comparison ( $n=24 / 60=40 \%$ ) group negotiators formed contingent contracts as did Baseline $(n=50 / 213=$ $23 \%$ ) and Separate Cases $(n=8 / 37=22 \%)$ group negotiators, a reliable association, $\chi^{2}(N=310,2)=$ 7.08, $p<.05$ (see Figure 1). Thus, drawing comparisons facilitated learning the contingent contract schema from examples and applying it to a novel face-to-face negotiation situation.

We also explored a comparison advantage on expected joint gains (i.e., negotiation performance). Comparison group participants ( $M=\$ 4.76$ million; $S D=\$ 1.04$ million) generated contracts of greater value than the Separate Cases group participants ( $M=\$ 4.28$ million; $\mathrm{S} D=\$ 1.17$ million) or a random sample of Baseline participants $(N=39$; $M=\$ 4.19$ million; $S D=\$ 0.89$ million), $F(2,133)=$

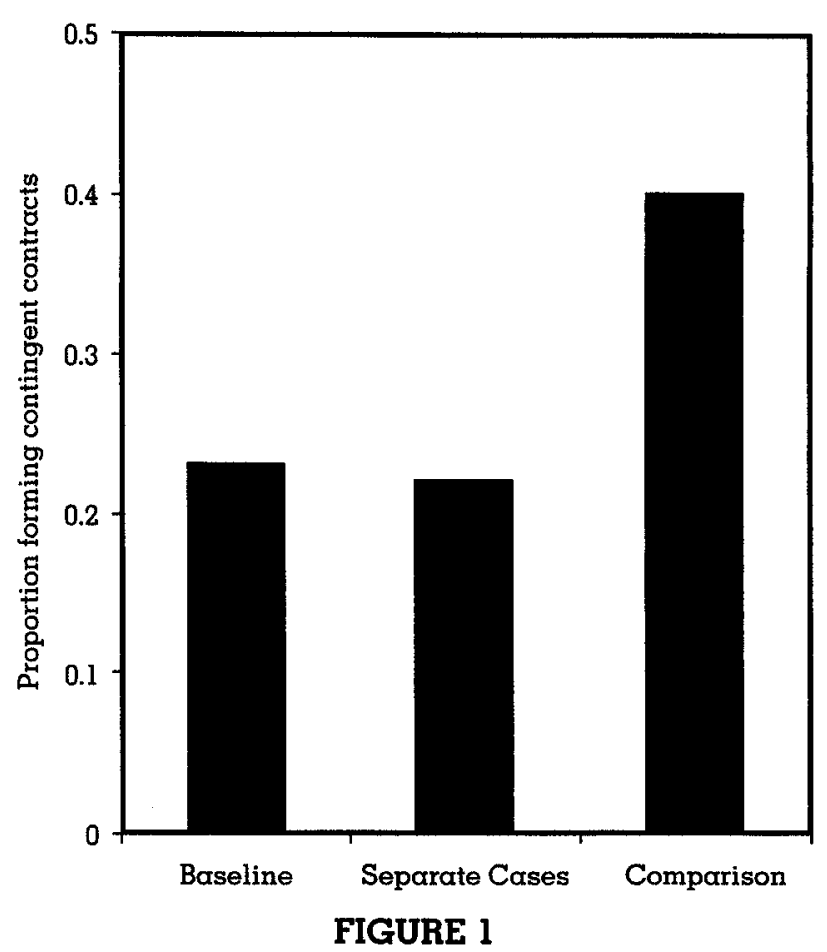

Proportion of Negotiation Groups Forming Contingent Contracts by Training Condition

4.35, $p<.05$. Post hoc tests of mean differences confirmed that the Comparison group contracts were of reliably higher value than those of both the Separate Cases and Baseline groups, which did not differ reliably from each other. As expected, participants who formed contingent contracts ( $n=$ 39; $M=\$ 5.33$ million; $S D=\$ 1.00$ million) attained higher expected joint gains than participants who did not $(n=97 ; M=\$ 4.12$ million; $S D=\$ 0.88$ million), $t(134)=6.99, p<.001$.

\section{Content Coding of Team Reports}

Prior researchers have found that comparison focilitates transfer as a result of improving people's understanding of the training cases' structure (e.g., Loewenstein et al., 1999). Raters blind to the hypotheses of the study coded $40 \%$ of the responses as to whether they were complete, partial, or absent the contingent contract schema (following the methodology of Loewenstein et al., 1999, and Thompson et al., 2000). Those who drew comparisons (21/38, or .55) were more likely to induce the schema than were those who analyzed cases separately (12/38, or .32), a reliable difference, $\chi^{2}(N=$ $76,1)=4.34, p<.05$. Thus, drawing comparisons facilitated understanding the general principle underlying the examples. As a manipulation check to ensure that comparison groups were drawing comparisons and separate cases groups were not, we 
coded whether participants made reference to the first study case when discussing the second. As predicted, all Comparison condition participants explicitly described connections between the two examples, but only $18 \%$ of the Separate Cases condition participants did so. Many of these links were weak (e.g., "again, two parties reached an agreement by settling their differences"). Thus, it is likely that participants in the Separate Cases condition did not notice the common agreement structure across the training cases, despite being told to analyze the solutions to the cases.

\section{DISCUSSION}

The management educator and trainer faces two inextricably linked challenges: what to teach and how to teach. The substantive challenge focuses on what should be taught-the principles to be conveyed and practiced. The procedural challenge focuses on how to teach. We note that in the information age, management educators and trainers face a dizzying array of choices, with $\alpha$ partial list including didactic or principle-based training. experiential training, coaching, and case-based training. The business school world of management education continues to rely heavily on the case method. Our empirical investigation of analogical learning vis-à-vis the case method suggests that it can be improved without losing valuable content, by changing the learning process.

We found that comparing cases during a study session prior to a face-to-face negotiation led to greater understanding of the negotiation strategy (as evidenced by open-ended statements) and greater use of the strategy than did analyzing the cases separately. Further, comparison resulted in agreements with higher expected joint gains (about half a million dollars, in our simulation). These findings extend the analogical encoding advantages observed in studies of individuals to team learning.

We also found that knowledge transfer (i.e., the ability to apply the negotiation strategy in the study cases to resolve the face-to-face negotiation) among the Separate Cases training condition was low. In fact, these groups were no more likely to form contingent contracts than were groups receiving no training. In sum, comparison training promoted learning and transfer of negotiation principles, but separate case training resulted in inert knowledge-that is, people apparently encoded the cases, but did so in a contextually specific manner that obscured the deep similarities to the new case. This striking finding dramatizes the challenge of retrieving prior cases and the impor- tance of encouraging processes that illuminate the underlying structure of cases.

The phenomenon of learning by comparing two analogs may be very general. In our research, we have found advantages for learning by analogical encoding across several populations, two different negotiation principles, and several kinds of training and transfer materials. Benefits of comparison learning have also been found in other domains, such as mathematics and physics (Catrambone \& Holyoak, 1989; Glynn \& Takahashi, 1998; Kurtz, Mico, \& Gentner, 2001; Ross \& Kennedy, 1990), and across a wide range of ages (Gentner \& Namy, 1999; Loewenstein \& Gentner, 2001). Finally, benefits of intensive comparison learning experiences persist for at least months (Chen \& Klahr, 1999).

\section{Contrasts With Team Learning Phenomena}

Theories of group problem solving and decision making suggest that groups discuss the information they all know about rather than the information group members hold uniquely (Larson, Foster-Fishman, \& Keys, 1994; Stasser, Stewart, \& Wittenbaum, 1995). This tendency to discuss commonly held information may hold for surfacesimilar items, but not for structurally similar (and not surface-similar) information. Our analyses of the team training essays did not suggest that spontaneous comparison of the training materials occurred in the Separate Cases condition. Rather, teams focused on general features of the situation that were not particularly helpful in suggesting a resolution (e.g., " $\alpha$ successful negotiation is one where both parties are happy with the outcome," or "family issues are tricky"); and tended to rehash the superficial, contextual information presented in the case (e.g., "Syd wants to ensure the boots arrive but also is interested in a longer term relationship with $\alpha$ major firm ..."). Further, teams who studied cases separately showed very little linking across examples. Common information effects may be largely limited to surface similarities held across parties.

The purpose of the case training was to allow learners to acquire $\alpha$ general understanding of the contingent contract schema. This schema is conceptually unitary, in the sense that it probably cannot be meaningfully distributed across individuals. For this reason, we suggest that teams may have an advantage relative to individuals if the concept to be acquired can be distributed, but may be at a disadvantage if it is unitary. The availability of many cooks may be ideal for making fruit salad, but not a soufflé; many hands may be ideal for putting together the many parts of a radio, but 
a single set of hands may be best when sitting at the potter's wheel. Accordingly, we include in Table 1 additional data from individuals who were provided the same training materials and negotiation test case as the current teams. As shown by our collected data (Table 1), individual training appears to yield greater benefits for acquiring the contingent contract schema than team training, given individual performance.

Although groups may exchange more information than individual negotiators, there may only be $\alpha$ weak link between information exchange and forming contingent contracts. Thompson, Peterson, and Brodt (1996) found that groups exchange more information than individuals and that information exchange was directly tied to forming trade-offs (wherein parties create value by yielding on lowpriority issues to make gains on high-priority issues). However, in related pilot research, we have found that negotiating groups do not all discuss their difference of opinion about the future, those who discuss it do not all propose contingencies, and those that propose contingencies do not all form contingent agreements. Forming contingent agreements may require a level of trust and monitoring beyond trade-off agreements, and may appear less legitimate than trade-offs as a result (e.g., occasionally we find people who tell us "I would never bet on something as significant as this"; Lax \& Sebenius, 1986). As team negotiations may be more contentious than individual negotiations (Schopler \& Insko, 1992), this may be a countervailing tendency to the benefit of greater information sharing among groups.

\section{Implications for Management Education and Training}

The advantage of comparison is that it can make complex knowledge portable. Professional training, including management, law, and medical training, relies heavily on cases. This is for good reasons: Cases possess sufficient complexity to capture the content domain of interest, and they are memorable. However, single cases are recalled in only limited, highly similar circumstances, such that most cases simply become part of the repository of inert knowledge that people have but never use. Comparison offers $\alpha$ means by which learners con capitalize on the richness of cases while fostering the acquisition of portable abstract principles. We speculate that the cognitive advantages of case comparison are quite general. Case comparison encourages appropriate analysis, inspires curiosity, and leads to abstracting principles. Thus, drawing on analogical learning theory, we suggest that drawing comparisons can advance the effectiveness of the case method.

We focused on negotiation skills because it has been argued that negotiation is the "core of the manager's job" (Lax \& Sebenius, 1986: 2). Negotiation also presents natural challenges to learning and transfer: They occur in real time, in emotionally charged situations, and across widely varying contexts. It is not surprising then, that untrained negotiators (even those with professional negotiation experience) often miss opportunities and leave money on the table. Thus, learning negotiation principles is both important and challenging. and that analogical encoding facilitated the acquisition of negotiation principles is a demonstration of its potential effectiveness.

If separate case study is not clearly better with respect to knowledge transfer than no training at all, then training may yield no tangible benefits. Savvy companies may not want to invest in training for transfer that does not provide opportunity for case comparison. Furthermore, educators should not expect learners to make comparisons spontaneously. We found both in the present investigation and our previous studies that few people not instructed to draw comparisons across surface-dissimilar cases actually do so. We have even found that directly telling people that studying the materials will help them in their upcoming negotiation was not sufficient to promote transfer. Apparently, the lure of elaborating upon individual case details can sidetrack group discussion. We are wary of uses of the case method for management education if they offer only a detailed analysis of a single instance.

Case comparison can be encouraged either through discussing multiple brief cases, as in the present research, or through identifying hypothetical variations of one larger case (Morris \& Moore, 2000; Williams, 1992). For example, classroom instructors can lead discussions on the commonalities and differences across cases. Not only might this provide immediate benefits in students' understanding, it might also suggest to students the metacognitive strategy of searching out comparison opportunities. It is not difficult to implement such changes in classroom discussions, and the gains may be substantial. If instructors are already using cases, then they can improve by presenting additional analogous examples (they can be quite brief) that highlight key aspects of the main case. If instructors are using abstract statements, it is worth the extra effort to consider at least two concrete instantiations-students frequently misunderstand and fail to remember bare presentations of abstract principles. Watch out for 
misleading commonalities along irrelevant dimensions or between two entities playing different roles. This is one reason to choose examples set in different contexts. Advanced students may need only the simple instruction to compare an example to the main case; novices will benefit from the instructor's help in finding correspondences between two instances. Instructors can also provide $\alpha$ "moral of the story" to help ensure that students are reaching a desired interpretation of the analogy.

It is useful to speculate about the conditions under which team-level training and, in particular. team-level analogical learning, may be most beneficial. We suggest that the particular benefit of teams is that they offer the potential to expand the range of analogies that might be applied to a current situation. If the task is to find an analogy to a single current problem, $\alpha$ group with diverse experiences should be more likely to find a useful analogy than a group with similar experiences or an individual (Dunbar, 1995; Hargadon \& Sutton, 1997). For example, Dunbar (1995) has found that microbiology research groups with diversely experienced group members stimulated novel solutions to each other's problems by drawing out analogies from their varied background knowledge. In contrast, in more homogeneous research groups, researchers tended to fail on the same problems-a limit that Dunbar attributed to a lack of analogies on which to draw.

\section{CONCLUSION}

Our research investigation focused on how best to teach negotiation cases so as to enhance learning. We found $\alpha$ consistent and powerful advantage for the analogical encoding method in which learners compare two cases over the more traditional and currently more popular method of teaching by single case studies. An obvious question, given the powerful effects observed under this short duration effect, is whether there are potential cumulative effects of processing comparisons over a series of learning opportunities. Our speculation is that repeated use of analogical encoding could accelerate conceptual change, yielding understanding of useful management principles that generalize well beyond the initial learning context.

\section{REFERENCES}

Argote, L. 1999. Organizational learning: Creating, retaining and transferring knowledge. Boston: Kluwer Academic Publishers.

Bazerman, M. H., \& Gillespie, J. J. 1999. Betting on the future: The virtues of contingent contracts. Harvard Business Review, 77(4): 155-160.

Brodt, S., \& Thompson, L. 2001. Negotiating teams: A levels of analysis approach. Group Dynamics: Theory Research and Practice, 5(3): 208-219.

Catrambone, R., \& Holyoak, K. J. 1989. Overcoming contextual limitations on problem-solving transfer. Journal of Experimental Psychology: Learning, Memory and Cognition, 15(6): 1147-1156.

Chen, Z., \& Klahr, D. 1999. All other things being equal: Acquisition and transfer of the Control of Variables Strategy. Child Development. 70(5): 1098-1120.

Davis, J. H. 1969. Group performance. Reading, MA: AdddisonWesley.

Diehl, M., \& Stroebe, W. 1987. Productivity loss in brainstorming groups: Toward a solution of a riddle. Journal of Personality and Social Psychology, 53: 497-509.

Dunbar, K. 1995. How scientists really reason: Scientific reasoning in real-world laboratories. In R. J. Sternberg \& J. E. Davidson (Eds.), The nature of insight: 365-395. Cambridge, MA: MIT Press.

Faraj, S., \& Sproull, L. 2000. Coordinating expertise in software development teams. Management Science, 46(12): $1554-1568$.

Gentner, D. 1989. The mechanisms of analogical learning. In S. Vosniadou \& A. Ortony (Eds.), Similarity and analogical reasoning: 199-241. New York: Cambridge University Press.

Gentner, D. 1983. Structure-mapping: A theoretical framework for analogy. Cognitive Science, 7:155-170.

Gentner, D., Holyoak, K. J., \& Kokinov, B. N. 2001. The analogical mind. Cambridge, MA: MIT Press.

Gentner, D., \& Landers, R. 1985. Analogical reminding: A good match is hard to find. Proceedings of the International Conference on Cybernetics and Society: 607-613. Tucson. AZ. New York: Institute of Electrical and Electronics Engineers.

Gentner, D., \& Markman, A. B. 1997. Structure-mapping in analogy and similarity. American Psychologist, 52(1): 45-56.

Gentner, D., \& Namy, L. 1999. Comparison in the development of categories. Cognitive Development, 14: 487-513.

Gentner, D., Rattermann, M. J., \& Forbus, K. D. 1993. The role of similarity in transfer: Separating retrievability from inferential soundness. Cognitive Psychology, 25(4): 524-575.

Gick, M. L., \& Holyoak, K. J. 1980. Analogical problem solving. Cognitive Psychology, 12: 306-355.

Glynn, S. M., \& Takahashi, T. 1998. Learning from analogyenhanced science text. Journal of Research in Science Teaching, 35(10): 1129-1149.

Gregan-Paxton, J., \& Roedder John, D. 1997. Consumer learning by analogy: $A$ model of internal knowledge transfer. Journol of Consumer Research, 24, 266-284.

Halpern, D. F. 1998. Teaching critical thinking for transfer across domains. American Psychologist, 53(4): 449-455.

Hargadon, A., \& Sutton, R. I. 1997. Technology brokering and innovation in a product development firm. Administrative Science Quarterly, 42(4): 716-749.

Holyoak, K. J., \& Koh. K. 1987. Surface and structural similarity in analogical transfer. Memory \& Cognition, 15: 332-340.

Insko, C., \& Schopler, J. 1987. Categorization, competition, and 
collectivity. In C. Hendrick (Ed.), Group processes: 213-251. Beverly Hills. CA: Sage.

Isenberg, D. J. 1986. Thinking and managing: $A$ verbal protocol analysis of managerial problem solving. AcademY of Management Journal, 29(4): 775-788.

Keane, M. T. 1988. Analogical problem solving. New York: Ellis Horwood, Ltd., Halsted Press.

Kurtz, K. J., Miao, C.-H., \& Gentner, D. 2001. Learning by analogical bootstrapping. Journal of the Learning Sciences, 10(4): 417-446.

Larson, J. R., Foster-Fishman, P. G., \& Keys, C. B. 1994. Discussion of shared and unshared information in decision-making groups. Journal of Personality \& Social Psychology, 67(3): 446-461.

Lax, D. A., \& Sebenius, J. K. 1986. The manager as negotiator. New York: The Free Press.

Lewicki, R. J. 1997. Teaching negotiation and dispute resolution in colleges of business: The state of the practice. Negotiation Journal, 13(3): 253-269.

Loewenstein, J., \& Gentner, D. 2001. Spatial mapping in preschoolers: Close comparisons facilitate far mappings. Journal of Cognition and Development, 2(2): 189-219.

Loewenstein, J., Thompson, L., \& Gentner, D. 1999. Analogical encoding facilitates knowledge transfer in negotiation. Psychonomic Bulletin and Review, 6(4): 586-597.

Morris, M. W., \& Moore, P. C. 2000. The lessons we (don't) learn: Counterfactual thinking and organizational accountability after a close call. Administrative Science Quarterly, 45(4): 737-765.

O'Connor, K. 1997. Groups and solos in context: The effects of accountability on team negotiation. Organizational Behavior and Human Decision Processes, 72: 384-407.

Paulus, P. B., \& Dzindolet, M. T. 1993. Social influence processes in group brainstorming. Joumal of Personality and Social Psychology, 64: 575-586.

Pfeffer, J., \& Sutton, R. I. 2000. The knowing-doing gap. Boston, MA: Harvard Business School Press.

Ross, B. H. 1984. Remindings and their effects in learning a cognitive skill. Cognitive Psychology, 16: 371-416.
Ross, B. H. 1987. This is like that: The use of earlier problems and the separation of similarity effects. Journal of Experimental Psychology: Learning, Memory, and Cognition, 13(4): $629-639$.

Ross, B. H., \& Kennedy, P. T. 1990. Generalizing from the use of earlier examples in problem solving. Journal of Experimental Psychology: Learning. Memory, and Cognition, 16, 42-55.

Schopler, J., \& Insko, C. 1992. The discontinuity effect in interpersonal and intergroup relations: Generality and mediation. In W. Stroebe \& M. Hewstone (Eds.), European review of social psychology: 121-151. Chichester, England: Wiley.

Schumacher, R., \& Gentner, D. 1987, May. Similarity-based remindings: The effects of similarity and interitem distance. Paper presented at the Midwestern Psychological Association, Chicago, Il.

Schwartz, D. L. 1995. The emergence of abstract representations in dyad problem solving. Journal of the Learning Sciences. 4: $321-354$

Stasser, G., Stewart, D. D., \& Wittenbaum, G. M. 1995. Expert roles and information exchange during discussion: The importance of knowing who knows what. Journal of Experimental Social Psychology, 31: 244-265.

Steiner, I. 1972. Group processes and productivity. New York: Academic Press.

Thompson, L., Gentner, D., \& Loewenstein, J. 2000. Avoiding missed opportunities in managerial life: Analogical training more powerful than individual case training. Organization Behavior and Human Decision Processes, 82(1): 60-75.

Thompson, L., Peterson, E., \& Brodt, S. 1996. Team negotiation: An examination of integrative and distributive bargaining. Journal of Personality and Social Psychology, 70(1): 66-78.

Wheeler, M. 2000. Teaching negotiation: Ideas and innovations. Cambridge, MA: PON Books.

Williams, S. M. 1992. Putting case-based instruction into context: Examples from legal and medical education. The Journal of the Learning Sciences, 2(4): 367-427.

Wittenbaum, G. M., \& Stasser, G. 1996. Management of information in small groups. In J. L. Nye \& A. M. Brower, (Eds.), What's social about social cognition? Research on socially shared cognition in small groups: $3-28$. Thousand Oaks, CA; Sage.

Jeffrey Loewenstein is a contract assistant professor of management at the Columbia Business School. He earned his $\mathrm{PhD}$ in cognitive psychology at Northwestem University. His research focuses on the roles analogy and language play in learning.

Leigh Thompson is the J. Jay Gerber Distinguished Professor of Dispute Resolution and Organizations at the Kellogg School of Management at Northwestern University. Thompson earned her $\mathrm{PhD}$ in social psychology at Northwestern University. She investigates how cognition and emotion affect managers' ability to perform organizational activities.

Dedre Gentner is a professor of psychology as well as education and social policy, and is the director of the Cognitive Science Program at Northwestern University. Gentner earned her $\mathrm{PhD}$ in cognitive psychology from the University of California at San Diego. Her research addresses topics including learning, language and thought, analogy, metaphor and similarity, and mental models. 